\title{
Prevalence and severity of hypoglycemia in a sample of neonates in Erbil city
}

\begin{tabular}{ccc}
\hline Ahmed S. Rajab $*$ & Dlair A.K. Chalabi $* *$ & Abbas A. Al-Rabaty $* *$ \\
\hline Abstract \\
\end{tabular}

Background and objective: Transient hypoglycemia may affect the newborn in the first hour of life and is the most prevalent metabolic disorder. The maternal-fetal diffusion that keeps the fetal glucose level nearly two thirds of the maternal glucose concentration. This study aimed to identify the prevalence of hypoglycemia and detect certain demographic and maternal factors that may be associated with and their relation to neonatal blood glucose level.

Methods: A prospective cross-sectional study was conducted in Erbil Maternity Teaching Hospital in Erbil city during a period of 4 months, from February $1^{\text {st }}$ to May $31^{\text {st }}, 2013$. A total of 400 newborns from the neonatal care unit and the delivery and waiting rooms were included in the study. All of them were less than 3 hours of age and didn't receive oral feeding.

Results: Among 400 neonates, 65 were hypoglycemic confirmed by serum sample with a prevalence of $16.25 \%$ during the first 3 hours. Most of the screened neonates were male (male: female ratio 1,45: 1). A highly significant association was found between neonatal hypoglycemia with preterm babies and hypoglycemic mother. Grand multiparity, low birth weight and head circumference also may predispose to hypoglycemia while mean length of affected babies was lower than the normoglycemic group. The severity of hypoglycemia was significantly associated with gestational age, birth weight and maternal serum glucose status.

Conclusion: Hypoglycemia is present in relatively high frequency among newly born babies and certain factors like prematurity, low birth weight and maternal hypoglycemia can predict its occurrence and its severity.

Keywords: Gestational age; Hypoglycemia; Maternal; Neonatal.

\section{Introduction}

Hypoglycemia is a common metabolic disorder but its definition remained controversial because of a lack of significant correlation among plasma glucose concentration, clinical symptoms, and long-term sequel. ${ }^{1,2}$ Approaches to defining hypoglycemia have included a statistical approach with standard deviations, counter-regulatory responses with a metabolic approach, neurophysiological changes, and neurodevelopmental outcomes of symptomatic versus asymptomatic hypoglycemia. ${ }^{3}$ Definitions varies from less than $30 \mathrm{mg} / \mathrm{dl}$ in the first 24 hours to less than $45 \mathrm{mg} / \mathrm{dl}^{4,5}$ or from less than $2 \mathrm{mmol} /$ $\mathrm{L}$ to less than $2.6 \mathrm{mmol} / \mathrm{L}$. ${ }^{6,7}$ Accompanied symptoms include jitteriness, cyanosis, seizures, apneal episodes, tachypnea, weak or high-pitched cry, floppiness or lethargy, poor feeding, and eye-rolling. ${ }^{8,9}$ The normal range of blood glucose is different for each newborn and depends upon a number of factors including birth-weight, gestational age, body stores, feeding status, availability of energy sources as well as the presence or absence of disease. ${ }^{8}$ The new definition of the neonatal hypoglycemia is when blood

* Department of Pediatric, Rapareen Teaching Hospital, Erbil, Iraq.

** Department of Pediatric, College of Medicine, Hawler Medical University, Erbil, Iraq. 
glucose less than $(2.6 \mathrm{mmolV}$ or less than $46 \mathrm{mg} / \mathrm{dl}){ }^{7}$ Many conditions may lead to hypoglycemia. The factors that increase the risk of developing neonatal hypoglycemia can be summarized into 1) decreased substrate availability such as prematurity and inborn error of metabolism, 2) hyperinsulinemia such as infant of diabetic mother and Islet cell hyperplasia, 3) other endocrine abnormalities such as pan-hypopituitarism and 40 increased glucose utilization such as cold stress and sepsis. This study aimed to identify the prevalence of hypoglycemia and detect certain demographic and maternal factors that may be associated with and their relation to neonatal blood glucose level.

\section{Methods}

A prospective cross-sectional study conducted during a period of 4 months, from February $1^{\text {st }}$ to May $31^{\text {st }}, 2013$, in Erbil Maternity Teaching Hospital which is the only maternity teaching hospital in Erbil city with a total number of 400 newborns were included (from NCU, delivery room and waiting room), all of them were less than 3 hours of age and didn't receive oral feeding as it may affect results. ${ }^{5}$ For the purpose of the study, they were divided into three groups: less than 1 hours, between 1 to 2 hours and finally more than 2 hours but less than $3 \mathrm{hrs}$. All neonates (regardless gestational age and birth weight) who did not receive any oral intake or medication or IV fluid of non-diabetic mother were included. Conditions need intensive care unit or with the underlying disease like hydrops fetalis or had any major congenital anomalies and those who started feeding were excluded from the study. Blood glucose of newborns and their mothers had been obtained for the sake of the study. Mothers were checked in the last 6hr before delivery, before receiving any drug or IV fluid. Hypoglycemia was defined as blood sugar levels less than $46 \mathrm{mg} / \mathrm{dl}$ (2.6 $\mathrm{mmol} / \mathrm{l}$ ) in the $1 \mathrm{st} 3$ hours of life., While maternal hypoglycemia is when level below $88 \mathrm{mg} / \mathrm{dl}$ and maternal hyperglycemia when level above $135 \mathrm{mg} / \mathrm{dl}^{12}$ Multiple pregnancies consist of two or more fetuses $^{13}$ and $A$ reasonable definition of Grand Multiparity is $\geq 5$ live births. ${ }^{14}$ Among 400 neonates screened for hypoglycemia in the first 3 hours of life, 139 had plasma glucose less than 2.6 $\mathrm{mmol} / \mathrm{L}$ by using the glucose meter and undergone serum glucose test where 65 confirmed having hypoglycemia and were considered as the hypoglycemic group. For the aim of the study to find an association, 135 neonates with normal initial glucose level and no associated major fetal or maternal disease considered as the normoglycemic group after excluding 200 neonates with inadequate data or lack of their maternal blood glucose level. Then we divided the hypoglycemic group into three subgroups according to serum glucose level. Written consent had been taken from all the families were their babies included in this study, after explaining the purpose and aim of the study to them. The weight, length and OFC were measured for all neonates, and the results plotted on the special growth chart for fetus and infant according to their gestational weeks. ${ }^{15}$ According to anthropometric measurements, the babies divided into three groups. The first group was below the $10^{\text {th }}$ percentile, the second group was between $10^{\text {th }}$ and $90^{\text {th }}$ percentile, and the last group was more than the $90^{\text {th }}$ percentile. The weight scale device (Berure) used to measure body weight for all babies; it is a digital baby scale with a curved weighing platform. Babies were cleaned immediately after birth with the weighing scale put on a flat, stable surface. Then, the naked baby kept on the towel and recorded the weight with abstracting the weight of the towel.

\section{Collection of samples:}

Samples taken by a prick in the heel of the neonates, after sterilization by using alcohol $95 \%$. The $1^{\text {st }}$ drop was removed to decrease the contamination; with the $2^{\text {nd }}$ drop, the result was recorded. Glucometer with strips was used for screening of 
hypoglycemia with capillary blood samples obtained by heel prick, then a confirmatory sample $(1 \mathrm{~mL}$ of blood from a peripheral vein) to measure plasma glucose level by spectrophotometric method. ${ }^{16}$ The device (glucometer), which was used, was named "ACCU check device."

\section{Statistical analysis:}

Data were analyzed using the statistical package for the social sciences (version 19). Chi-square test of association was used to compare between proportions and Fisher's exact test used instead of the Chi-square test when $20 \%$ of expected frequencies are less than or equal to 5 while Student's t-test was used to compare between means. Risk Estimate (odds ratio and confidence interval, OR \& $\mathrm{Cl}$ ) computed for a 2x2 table.
A $P$ value of $\leq 0.05$ was considered statistically significant.

\section{Results}

Among 400 neonates, sixty-five of them were hypoglycemic confirmed by serum sample with a prevalence of $16.25 \%$ during the first 3 hours, most of the screened neonates were male (male: female ratio $1.45: 1)$ and product of vaginal delivery (233, 58.3\%). Table 1 shows that a highly significant association was found between neonatal hypoglycemia with gestational age as high rates occurred in those $<37$ and $>42$ weeks while hypoglycemic mother was more likely to have hypoglycemia in their babies. Grand multiparity, low birth weight and head circumference also may predispose to hypoglycemia.

Table 1: Relation of certain demographic, obstetrical and clinical data with neonatal hypoglycemia

\begin{tabular}{|c|c|c|c|c|c|}
\hline Variables & & $\begin{array}{c}\text { Hypogly. } \\
(n=65)\end{array}$ & $\begin{array}{c}\text { Normogly. } \\
(n=135)\end{array}$ & $P$ value & OR $(\mathrm{CI})^{\#}$ \\
\hline Age (hours)* & $\begin{array}{l}<1 \mathrm{hr} \\
1 \mathrm{hr} \text { to } 2 \mathrm{hr} \\
>2 \mathrm{hr}\end{array}$ & $\begin{array}{c}34(33.3) \\
28(36.8) \\
3(13.6)\end{array}$ & $\begin{array}{l}68(66.7) \\
48(63.2) \\
19(86.4)\end{array}$ & 0.11 & \\
\hline Mode of delivery & $\begin{array}{l}\text { Caesarean } \\
\text { Vaginal }\end{array}$ & $\begin{array}{l}38(36.9) \\
27(27.8)\end{array}$ & $\begin{array}{l}65(63.1) \\
70(72.2)\end{array}$ & 0.17 & $\begin{array}{c}1.51 \\
(0.834-2.756)\end{array}$ \\
\hline Gender & $\begin{array}{l}\text { Male } \\
\text { Female }\end{array}$ & $\begin{array}{l}34(28.1) \\
31(39.2)\end{array}$ & $\begin{array}{l}87(71.9) \\
48(60.8)\end{array}$ & 0.10 & $\begin{array}{c}0.60 \\
(0.33-1.10)\end{array}$ \\
\hline $\begin{array}{l}\text { Gestational } \\
\text { age }(G A)^{*}\end{array}$ & $\begin{array}{l}<37 \\
37-42 \\
>42\end{array}$ & $\begin{array}{c}33(51.6) \\
27(20.9) \\
5(71.4)\end{array}$ & $\begin{array}{c}31(48.4) \\
102(79.1) \\
2(28.6)\end{array}$ & $<0.001$ & \\
\hline Parity & $\begin{array}{l}\text { Grand Multiparity } \\
\text { Not }\end{array}$ & $\begin{array}{c}17(50) \\
48(28.9)\end{array}$ & $\begin{array}{c}17(50) \\
118(71.1)\end{array}$ & 0.017 & \\
\hline Weight in percentile* & $\begin{array}{l}<10 \mathrm{PC} \\
10-90 \mathrm{PC} \\
>90 \mathrm{PC}\end{array}$ & $\begin{array}{c}24(55.8) \\
32(24.4) \\
9(34.6)\end{array}$ & $\begin{array}{l}19(44.2) \\
99(75.6) \\
17(65.4)\end{array}$ & 0.001 & \\
\hline Length in percentile* & $\begin{array}{l}<10 \mathrm{PC} \\
10-90 \mathrm{PC} \\
>90 \mathrm{PC}\end{array}$ & $\begin{array}{c}21(44.7) \\
39(28.3) \\
5(33.3)\end{array}$ & $\begin{array}{l}26(55.3) \\
99(71.7) \\
10(66.7)\end{array}$ & 0.11 & \\
\hline $\begin{array}{l}\text { Head circumference } \\
\text { in percentile* }\end{array}$ & $\begin{array}{l}<10 \mathrm{PC} \\
10-90 \mathrm{PC} \\
>90 \mathrm{PC}\end{array}$ & $\begin{array}{c}17(53.1) \\
40(26.1) \\
8(53.3)\end{array}$ & $\begin{array}{c}15(46.9) \\
113(73.9) \\
7(46.7)\end{array}$ & 0.002 & \\
\hline $\begin{array}{l}\text { Maternal } \\
\text { hypoglycemia }\end{array}$ & $\begin{array}{l}\text { Yes } \\
\text { No }\end{array}$ & $\begin{array}{c}18(90) \\
47(26.1)\end{array}$ & $\begin{array}{c}2(10) \\
133(73.9)\end{array}$ & $<0.001$ & $\begin{array}{c}25.46 \\
(5.69-113.94)\end{array}$ \\
\hline Type of pregnancy & $\begin{array}{l}\text { Single pregnancy } \\
\text { Multiple pregnancies }\end{array}$ & $\begin{array}{c}60(31.7) \\
5(45.5)\end{array}$ & $\begin{array}{c}129(68.3) \\
6(54.5)\end{array}$ & 0.34 & $\begin{array}{c}0.55 \\
(0.16-1.90)\end{array}$ \\
\hline
\end{tabular}


Unlike its frequency (Table 1), the mean of each growth parameter is significantly associated with low serum glucose as shown in Table 2. The severity of hypoglycemia is affected by gestational age, birth weight and maternal serum glucose status as revealed in Table 3.

Table 2: $\mathrm{T}$ test relating certain variables with neonatal hypoglycemia.

\begin{tabular}{lccc}
\hline Variables & $\begin{array}{c}\text { Hypoglycemia } \\
\text { mean (SD) }\end{array}$ & $\begin{array}{c}\text { Normoglycemia } \\
\text { mean (SD) }\end{array}$ & $\boldsymbol{P}$ value \\
\hline Weight $(\mathrm{cm})$ & $2.76(1.24)$ & $3.18(0.79)$ & 0.004 \\
Length $(\mathrm{cm})$ & $45.70(5.33)$ & $48.47(2.95)$ & $<0.001$ \\
Head circumference $(\mathrm{cm})$ & $32.53(2.88)$ & $34.17(1.62)$ & $<0.001$ \\
Maternal blood glucose $(\mathrm{mg} / \mathrm{dl})$ & $117.20(26.15)$ & $114.70(17.11)$ & 0.42 \\
\hline
\end{tabular}

Table 3: blood glucose level in relation to certain demographic and clinical data.

\begin{tabular}{|c|c|c|c|c|c|}
\hline \multirow[b]{2}{*}{ Variable } & \multicolumn{5}{|c|}{ Blood glucose level in hypoglycemic neonates } \\
\hline & & $\begin{array}{c}<35 \\
(n=12)\end{array}$ & $\begin{array}{l}35-40 \\
(n=19)\end{array}$ & $\begin{array}{c}>40 \\
(n=34)\end{array}$ & $P$ value \\
\hline \multirow[t]{3}{*}{ Age (hours)* } & $<1 \mathrm{hr}$ & $7(20.6)$ & $11(32.4)$ & $16(47.1)$ & \multirow{3}{*}{0.18} \\
\hline & $1 \mathrm{hr}$ to $2 \mathrm{hr}$ & $4(14.3)$ & $6(21.4)$ & $18(64.3)$ & \\
\hline & $>2 \mathrm{hr}$ & $1(33.3)$ & 2(66.7) & $0(0)$ & \\
\hline Gender & Male gender & $7(20.6)$ & $11(32.4)$ & $16(47.1)$ & 0.67 \\
\hline \multirow{3}{*}{$\begin{array}{l}\text { Gestational } \\
\text { age (weeks) }\end{array}$} & $<37$ & $9(27.3)$ & $13(39.4)$ & $11(33.3)$ & \multirow{3}{*}{0.02} \\
\hline & $37-42$ & $2(7.4)$ & $6(22.2)$ & $19(70.4)$ & \\
\hline & $>42$ & $1(20)$ & $0(0)$ & $4(80)$ & \\
\hline \multirow{3}{*}{$\begin{array}{l}\text { Weight in } \\
\text { percentile* }\end{array}$} & $<10 \mathrm{PC}$ & $7(29.2)$ & $11(45.8)$ & $6(25)$ & \multirow{3}{*}{0.01} \\
\hline & 10th -90th PC & $3(9.4)$ & $7(21.9)$ & $22(68.8)$ & \\
\hline & $>90 \mathrm{PC}$ & $2(22.2)$ & $1(11.1)$ & $6(66.7)$ & \\
\hline \multirow{3}{*}{$\begin{array}{l}\text { Length in } \\
\text { percentile* }\end{array}$} & $<10 \mathrm{PC}$ & $5(23.8)$ & $8(38.1)$ & $8(38.1)$ & \multirow{3}{*}{0.40} \\
\hline & 10th -90th PC & $6(15.4)$ & $9(23.1)$ & $24(61.5)$ & \\
\hline & $>90 \mathrm{PC}$ & $1(20)$ & $2(40)$ & $2(40)$ & \\
\hline \multirow{3}{*}{$\begin{array}{l}\text { Head } \\
\text { circumference } \\
\text { in percentile }\end{array}$} & $<10 \mathrm{PC}$ & $4(23.5)$ & $6(35.3)$ & $7(41.2)$ & \multirow{3}{*}{0.78} \\
\hline & 10th -90th PC & $6(15)$ & $11(27.5)$ & $23(57.5)$ & \\
\hline & $>90 \mathrm{PC}$ & $2(25)$ & $2(25)$ & $4(50)$ & \\
\hline $\begin{array}{l}\text { Type of } \\
\text { pregnancy }\end{array}$ & $\begin{array}{l}\text { Single } \\
\text { pregnancy }\end{array}$ & $12(20)$ & $18(30)$ & $30(50)$ & 0.57 \\
\hline $\begin{array}{l}\text { Mode of } \\
\text { delivery }\end{array}$ & Caesarean & $9(23.7)$ & $9(23.7)$ & $20(52.6)$ & 0.31 \\
\hline $\begin{array}{l}\text { Maternal s. } \\
\text { glucose status }\end{array}$ & Hypoglycemia & $4(22.2)$ & $9(50)$ & $5(27.8)$ & 0.03 \\
\hline
\end{tabular}




\section{Discussion}

Prevalence of hypoglycemia was $16.25 \%$, which is relatively higher than many studies may be due to the cutoff level of defining hypoglycemia was higher, according to our reference (most studies define it as $<40$ $\mathrm{mg} / \mathrm{dl}$ or even lower according to hours of age) and some studies include older aged babies. Ayoub $\mathrm{N}$ et al. studied 612 neonates admitted to the special care unit at the pediatric central hospital in Iraq, and 96 were hypoglycemic $(15.68 \%)$ but they included even diabetic mothers and hypoglycemia was defined as blood glucose level less than $35 \mathrm{mg} / \mathrm{dl}$ and not only in the first 3 hours. ${ }^{17}$ Blood glucose drops naturally in the first few hours after birth before normalizing; newborns have increased ability to utilize ketones/lactate for energy. ${ }^{7}$ Age in hours was considered in many studies to detect early and severe drop in blood glucose level, especially in infants of diabetic mothers, in this study time was restricted to first 3 hours while other previous studies where first 24 hours and even later days. Kaplan-Meier analysis displays infants that remain at risk for severe neonatal hypoglycemia plotted against the age when neonatal hypoglycemia was diagnosed first. Within the first hour of life, $9.3 \%$ were diagnosed; $3.5 \%$ were diagnosed during the next 4 hours so earlier screening can detect hypoglycemia and even severity. ${ }^{18}$ Our study didn't find an association between age in hours and severity as it is restricted to more limited time than most other studies. Gender was not a significant factor in neonatal hypoglycemia of non-diabetic mothers as Pal et al. ${ }^{6}$ and DePuy et al. ${ }^{19}$ revealed in their studies. This study showed significant association of growth parameters whether in percentile or mean in relation to hypoglycemia unlike most other studies with nearly similar design ${ }^{6}$, 18,19 except for Low birth weight (less than $2.5 \mathrm{~kg}$ ) increase risk by 2.19 (OR) as Ayoub et al. found in a study conducted in Baghdad. ${ }^{17}$ SGA (small for gestational age) was considered one of the common risk factors with the prevalence of $14.7 \%$ compared to LGA (large for gestational age, $8.1 \%$ ) in a study involved products of non diabetic mothers. ${ }^{16}$ As other articles reported, caesarean section (CS) or vaginal delivery (VD) were not significantly related to the occurrence of hypoglycemia. ${ }^{17-20}$ Even when subclassified to operative and spontaneous vaginal versus elective and non elective $\mathrm{CS}^{19}$, but there are many studies link duration and induced or augmented labor with neonatal hypoglycemia with a controversial result. Prematurity increase risk by more than two times ${ }^{17}$ that support significant relation with lower GA and hypoglycemia. Also, post term increase risk by 2.62 compared to term, ${ }^{1,3}$ and lower mean gestational age increase early hypoglycemia ${ }^{18,19}$ even when they are not premature versus term babies and this can be comparable to study results. Initially, in this work, we classified the parity to 3 intervals and association was poor, but when Grand Multiparity compared to lesser parity results were changed and become significantly associated with neonatal hypoglycemia despite available studies included multiparate in general versus primiparate didn't show a significant difference. ${ }^{6,17-19}$ The only explanation is that Grand Multiparity may increase the risk of having low birth weight babies so the occurrence of hypoglycemia. Ogunyemi et al. reported that Cesarean section and decreasing gestational age were the most consistent independent risk factors followed by SGA but sample include all babies, even diabetic mothers and those receive drugs during pregnancy. ${ }^{21}$ Zanardo et al. ${ }^{22}$ findings strongly support that Twin gestation is associated with higher rate of neonatal hypoglycemia than do singletons (OR: 2.49) and explained by higher rate of having small preterm babies and this disagree with our and another study results in Iraq, ${ }^{17}$ unfortunately limited data available about effect of multiple gestations and these controversial results may be 
attributed to the inclusion of the preterm babies only versus all newborns. Limited studies linked maternal hypoglycemia with neonatal hypoglycemia. DePuy et al ${ }^{19}$ showed no significant association with third trimester maternal glucose level. Here, in this study, the frequency of maternal hypoglycemia is highly associated with hypoglycemia after birth and it is related to severity. Many recommendations, including $\mathrm{WHO}$ suggest limiting intravenous glucose infusion to laboring women to avoid the development of neonatal hyperinsulinism and subsequent iatrogenic neonatal hypoglycemia. ${ }^{5,23}$ In contrary, there was a significant stepwise increase in severity of neonatal hypoglycemia within the first 24 hours of life in association with increased value of the maternal antenatal OGTT (oral glucose tolerance test). ${ }^{18}$ After review of many resources, no exact definition was present for severe hypoglycemia or relating level of hypoglycemia to certain factors. Researchers investigate risk factors for the severity of hypoglycemia; an unmatched case-control design was used to compare infants with moderate hypoglycemia (glucose less than $2.0 \mathrm{mmol} / \mathrm{l}$ ) with all other infants, using logistic regression, Two hundred and thirty eight (41\%) newborn infants had mild (less than $2.6 \mathrm{mmol} / \mathrm{l}$ ) and $66(11 \%)$ moderate hypoglycemia. Significant independent risk factors for moderate hypoglycemia included postmaturity (OR 2.62), birth weight under $2.5 \mathrm{~kg}$ (OR 2.11), small head size (OR $0.59)^{6}$ and these results were comparable to our results regarding these factors.

\section{Conclusion}

Hypoglycemia is present in relatively high frequency among newly born babies explained by the higher cutoff value in this study and certain factors like GA mainly prematurity, low birth weight and maternal hypoglycemia can predict its occurrence and its severity.

\section{Competing interests}

The authors declare that they have no competing interests.

\section{References}

1. Kalhan S, Peter-Wohl S. Hypoglycemia: What is it for the neonate? Am J Perinatol 2000; 17:11-8.

2. Boluyt $N$, van Kempen $A$, Offringa $M$. Neurodevelopment after neonatal hypoglycemia: A systematic review and design of an optimal future study. Pediatrics 2006; 117:2231-43.

3. Sweet CB, Grayson S, Polak M. Management Strategies for Neonatal Hypoglycemia. J Pediatr Pharmacol Ther 2013; 18(3):199-208.

4. Heck LJ, Erenberg A. Serum glucose levels in term neonates during the first 48 hours of life. J Pediatrics 1987;110(1):119-22.

5. Tanzer F, Yazar N, Yazar H, Icagansioglu D. Blood glucose levels and hypoglycemia in full term neonates during the first 48 hours of life. J Tropical Pediatrics 1997;43:58-60.

6. Pal DK, Manandhar DS, Rajbhandari S, Land JM, Patel $\mathrm{N}$, de $\mathrm{L}$ Costello AM. Neonatal hypoglycaemia in Nepal: Prevalence and risk factors. Arch Dis Child Fetal Neonatal Ed 2000; 82(1):46-51.

7. Johnston E. Hypoglycemia.in: Tasker R, McClure R, Acerini C. Oxford Handbook of Paediatrics. $2^{\text {nd }}$ ed. Oxford: Oxford University Press; 2013. P. 132.

8. Cornblath $M$, Ichord R. Hypoglycemia in the neonate. Semin Perinatol. 2000;24(2): 136-49

9. Rozance P, Hay W. Hypoglycemia in newborn infants: features associated with adverse outcomes. Biol Neonate 2006; 90(2):74-86.

10. Hawdon J, Ward Platt M, Aynsley-Green A. Patterns of metabolic adaptation for preterm and term infants in the first neonatal week. Arch Dis Child 1992; 67(4):357-65

11. Kalhan S, Parmimi P. Gluconeogenesis in the fetus and neonate. Semin Perinatol 2000; 24 (2):94-106.

12. Vadakekut ES1, McCoy SJ, Payton ME. Association of maternal hypoglycemia with low birth weight and low placental weight: a retrospective investigation. J Am Osteopath Assoc 2011; 111(3):148-52.

13. Jones G. Twins and Higher Multiple Gestations. In: Baker PN, Kenny LC,editors. Obstetrics by ten teachers. $19^{\text {th }}$ ed. London: Hodder \& Stoughton Ltd; 2011. P. 109

14. Simonsen SE, Varner MW. Grand-Multiparity. Accessed May,2016 at http://www.uptodate.com/ contents/grand-multiparity

15. Fenton TR, Kim JH. A systematic review and meta-analysis to revise the Fenton growth chart for preterm infants. BMC Pediatr 2013;13:59.

16. Holtrop P. The frequency of hypoglycemia in full term and small for gestational age newborns. Am J Perinatol 1993; 10:150-4. 
17. Ayoub N, Hanoudi BM, Naif MH. Evaluation of Maternal and Neonatal Risk factors for Neonatal Hypoglycemia. Iraqi J Comm Med 2013; 1:13-8.

18. Schaefer-Graf UM, Rossi R, Bührer C, Siebert G, Kjos SL, Dudenhausen JW, et al. Rate and risk factors of hypoglycemia in largefor-gestational-age newborn infants of non diabetic mothers. Am J Obstet Gynecol 2002; 187(4):913-7.

19. DePuy AM, Coassolo KM, Som DA, Smulian JC. Neonatal hypoglycemia in term, nondiabetic pregnancies. Am J Obstet Gynecol 2009; 200 (5):45-51.

20. de Freitas $P$, de Matos CV, Kimura AF.Profile of mothers of newborns with blood glucose control in the first hours of life. Rev Esc Enferm USP 2010; 44(3):636-41.

21. Ogunyemi $D$, Friedman $P$, Betcher $K$, Whitten A, Sugiyama N, Qu L, et al. Obstetrical Correlates and Perinatal Consequences of Neonatal Hypoglycemia in Term Infants. J Matern Fetal Neonatal Med 2016; 17:1-16.

22. Zanardo V, Cagdas S, Marzari F. Factors associated with neonatal hypoglycemia in premature twins and singletons. Acta Genet Med Gemellol (Roma) 1997; 46(1):69-77.

23. Haninger NC, Farley CL. Screening for hypoglycemia in healthy term Neonates: effects on breastfeeding. J Midwifery Womens Health 2001; 46(5):292-301. 